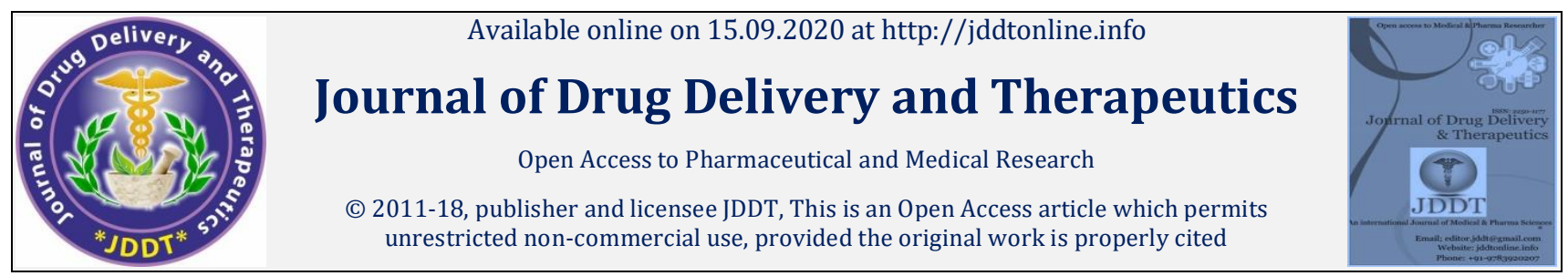

Open 1 Access

Research Article

\title{
Formulation and evaluation of gas powered systems of cefdinir tablets for controlled release
}

\author{
Manoj R. Chincholikar*, Jagdish Rathi \\ NRI Institute of Pharmaceutical Sciences, 3, Sajjan Singh Nagar, Raisen Rd, opposite Patel Nagar, Bhopal, Madhya Pradesh 462021, India
}

\begin{abstract}
The present work is aimed to formulate Cefdinir floating tablets using different hydrophilic and hydrophobic polymers like HPMC, Ethyl cellulose, Xanthum gum, guar gum and gas generating agent Sodium bicarbonate. The develop gastro retentive dosage form thatcould retain the agent namely Cefdinir in the stomach for longer periods of time delivering the drug to the site of action, i.e., stomach. HPMC is used as a swelling agent, Guar gum and Xanthum gum is used as binding agent. Ethyl cellulose is used as matrix form agent. PVP is used as a suspending agent. Sodium bicarbonate is used as a gas forming agent. MCC is used as a disintergrant and diluent. Magnesium stearate is used as a lubricant. The prepared Cefdinir tablets will be evaluated for drug content, entrapment efficiency, post compression studies, In-vitro buoyancy studies, swelling index studies, in-vitro dissolution studies, release kinetics, stability studies.All these parameters were found to be within the pharmacopoeial limits. Formulation F5 was selected for drug release and stability study on the basis of appropriate results of post compression study.In vitro dissolution study was carried out and showed controlled release pattern.
\end{abstract}

Keywords: Gas Powered Systems, Cefdinir, Controlled release, Floating drug delivery.

Article Info: Received 08 July 2020; Review Completed 21 Aug 2020; Accepted 30 August 2020; Available online 15 September 2020

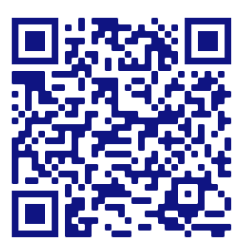

\section{Cite this article as:}

Chincholikar MR, Rathi J, Formulation and evaluation of gas powered systems of cefdinir tablets for controlled release, Journal of Drug Delivery and Therapeutics. 2020; 10(5):182-187 http://dx.doi.org/10.22270/jddt.v10i5.4310

*Address for Correspondence:

Manoj. R. Chincholikar, NRI Institute of Pharmaceutical Sciences, 3, Sajjan Singh Nagar, Raisen Rd, opposite Patel Nagar, Bhopal, Madhya Pradesh 462021

\section{INTRODUCTION}

Cefdinir is a broad-spectrum, semi synthetic, thirdgeneration cephalosporin. It possess a broad spectrum of activity, excellent therapeutic action against susceptible Gram-positive and Gram negative bacteria 1. It exhibits potent antimicrobial activity, excellent efficacy, convenient dosing and favourable tolerability compared with other antimicrobial agents ${ }^{2}$. It belongs to BCS Class IV with low solubility and low permeability characteristics. Cefdinir is available in only two dosage forms: capsules and suspension forms. Its show crystalline nature, with compressibility problem and thus, not formulated easily in tablet dosage form ${ }^{3}$. Various approaches have been proposed to control the residence of drug delivery systems in the upper part of the gastrointestinal tract like mucoadhesive systems, swelling/expanding systems, high density systems, magnetic systems, and floating systems ${ }^{4}$. Gastroretentive systems can remain in the gastric region for several hours and hence significantly prolong the gastric residence time of drugs. Prolonged gastric retention improves bioavailability, reduces drug waste, and improves solubility for drugs that are less soluble in a high $\mathrm{pH}$ environment. It has applications also for local drug delivery to the stomach and proximal small intestines. Gastro retention helps to provide better availability of new products with new therapeutic possibilities and substantial benefits for patients 5. The controlled gastric retention of solid dosage forms may be achieved by Mucoadhesion 6, Floatation 7, Sedimentation 8 , Expansion 9, Modified shape system 10 and Simultaneous administration of pharmacological agents ${ }^{11}$. Gastroretentive floating drug delivery system (GRFDDS) has bulk density lower than gastric fluids and thus remains buoyant in the stomach without affecting the gastric emptying rate for a prolonged period of time. While the system is floating on the gastric content, the drug is released slowly at a desired rate from the system. Floating drug delivery systems offer important advantages: as they are less prone to gastric emptying resulting in reduced intra and inter subject variability in plasma drug levels, effective for delivery of drugs with narrow absorption windows, reduced dosing and increased patient compliance, reduced Cmax and prolonged drug levels above the minimum effective concentration, and improved safety profile for drugs with side-effects associated with high Cmax 12,13. In the present study, a floating drug delivery system was designed and developed. The buoyancy principle providing floating dosage forms with prolonged 
gastric residence time seems to offer a greater safety of use compared to the other approaches. The tablets were prepared with effervescent component (sodium bicarbonate) using hydroxypropylmethylcellulose (HPMC) as a binder The prepared Cefdinir tablets evaluated for drug content, entrapment efficiency, post compression studies, In-vitro buoyancy studies, swelling index studies, in-vitro dissolution studies, release kinetics, stability studies.

\section{MATERIALS AND METHODS}

Cefdinir was supplied as a gift from M/s Hetero Drugs Ltd., Hyderabad, India. HPMC, Xanthum Gum, Guar Gum, PVP, Ethyl Cellulose, Sodium Bicarbonate, Micro Crystalline Cellulose, Magnesium Stearate were used of pharmaceutical grades. All other chemicals were used of analytical grade.

\section{Preparation of calibration curve of Cefdinir}

$100 \mathrm{mg}$ of Cefdinir was accurately weighted into $100 \mathrm{ml}$ volumetric flask, dissolved in $0.1 \mathrm{~N}$ HCL and volume was made up with $0.1 \mathrm{~N}$ HCL. Pipette $1 \mathrm{ml}$ of this solution into another $10 \mathrm{ml}$ volumetric flask and the volume was made with $0.1 \mathrm{~N} \mathrm{HCl}$ and marked as Stock. From this Cefdinir standard stock solution $(1000 \mu \mathrm{g} / \mathrm{ml}), 1 \mathrm{ml}$ solution was diluted to $10 \mathrm{ml}$ using $0.1 \mathrm{~N} \mathrm{HCl}$ solution to get concentrations of $100 \mu \mathrm{g} / \mathrm{ml}$. from this solution, aliquots of, $0.2 \mathrm{ml}, 0.4 \mathrm{ml}, 0.6 \mathrm{ml}, 0.8 \mathrm{ml}, 1.0 \mathrm{ml}, 1.2 \mathrm{ml}$ and $1.4 \mathrm{ml}$ from standard drug solution were diluted to $10 \mathrm{ml}$ with $0.1 \mathrm{M}$. The absorbance of these solutions was measured at $286 \mathrm{~nm} 0.1 \mathrm{~N}$ HCL as a blank.

\section{Formulation of cefdinir floating tablets}

All the formulations were prepared by direct compression method using different polymers Table 1.

1. Cefdinir and all other ingredients were individually passed through sieve $\neq 60$.

2. All the ingredients were mixed thoroughly by triturating up to $15 \mathrm{~min}$.

3. The powder mixture was lubricated with Magnesium stearate.

4. The tablets were prepared by using direct compression method according to the formulation table.

Table 1: Composition of different formulations

\begin{tabular}{|c|c|c|c|c|c|c|}
\hline Ingredients (mg) & F1 & F2 & F3 & F4 & F5 & F6 \\
\hline Cefdinir & 75 & 75 & 75 & 75 & 75 & 75 \\
\hline HPMC & 105 & 122.5 & 140 & -- & -- & -- \\
\hline Xanthum gum & -- & -- & & 105 & -- & -- \\
\hline Guar gum & -- & -- & & -- & 105 & -- \\
\hline Ethyl cellulose & -- & -- & & -- & -- & 105 \\
\hline PVP & 17.5 & 17.5 & 17.5 & 17.5 & 17.5 & 17.5 \\
\hline Sodium bicarbonate & 52.5 & 52.5 & 52.5 & 52.5 & 52.5 & 52.5 \\
\hline MCC & 96.5 & 79 & 61.5 & 96.5 & 96.5 & 96.5 \\
\hline Magnesium stearate & 3.5 & 3.5 & 3.5 & 3.5 & 3.5 & 3.5 \\
\hline Total weight & $350 \mathrm{mg}$ & $350 \mathrm{mg}$ & $350 \mathrm{mg}$ & $350 \mathrm{mg}$ & $350 \mathrm{mg}$ & $350 \mathrm{mg}$ \\
\hline
\end{tabular}

\section{Pre compression studies}

\section{Bulk density}

It is a ratio of mass of powder to bulk volume. The bulk density depends on particle size distribution, shape and cohesiveness of particles. Accurately weighed quantity of powder as carefully poured into graduated measuring cylinder through large funnel and volume was measured, which is called initial bulk volume. It is expressed in $\mathrm{gm} / \mathrm{ml}$ and is given by the formula:

\section{Bulk density=M/Vo}

Where, $\mathrm{M}=$ mass of the powder, $\mathrm{Vo}=$ bulk volume of the powder

\section{Angle of repose $(\theta)$}

It is defined as the maximum angle possible between the surface of the pile of the powder and the horizontal plane. Fixed funnel method was used. A funnel was fixed with its tip at a given height ' $h$, above a flat horizontal surface to which a graph paper was placed. Powder was carefully poured through a funnel till the apex of the conical pile just touches the tip of the funnel. The angle of repose was then calculated using following equation:

Angle of repose $\emptyset=\tan -1(\mathrm{~h} / \mathrm{r})$

Where, $\mathrm{h}=$ height of the pile, $\mathrm{r}=$ radius of the pile

\section{Tapped density}

Ten gram of powder was introduced into a clean, dry $100 \mathrm{ml}$ measuring cylinder. The cylinder was then tapped 100 times from a constant height and the tapped volume was read. It is expressed in $\mathrm{gm} / \mathrm{ml}$ and is given by:

$$
\text { Tapped density=M/Vt }
$$

Where, $\mathrm{M}=$ mass of the powder, $\mathrm{Vt}$ = final tapping volume of the powder

\section{Compressibility index (Carr's index)}

Compressibility index is used as an important parameter to determine the flow behavior of the powder. It is indirectly related to the relative flow property rate, cohesiveness and particle size. It is Simple, fast and popular method for predicting flow characteristics. Carr's index can be represented by Equation: 


$$
\text { Compressibility index }(\%)=\left[\frac{T D-B D}{T D}\right] \times 100
$$

\section{Hausner's ratio}

Hausner's ratio is used to predict the flow ability of the powders. This method is similar tocompressibility index. Hausner's ratio can be represented by Equation:

$$
\text { Hausner's ratio }=\frac{\text { Tapped density }}{\text { Bulk density }}
$$

\section{Evaluation of Prepared Formulation}

\section{Weight variation}

Randomly selected twenty tablets were weighed individually and together in a single pan balance. The average weight was noted and standard deviation calculated. The tablets pass the test if not more than two tablets fall outside the percentage limit and none of the tablet differs by more than double percentage limit.

$$
\mathrm{PD}=[(\text { Wavg }- \text { Winitial }) /(\text { Wavg) }] \times 100
$$

Where, $\mathrm{PD}=$ Percentage deviation, , Wavg = Average weight of tablet, , Winitial = Individual weight of tablet

\section{Thickness}

The thickness and diameter of tablets was determined using Vernier Caliper. Twenty tablets from each batch were used and average values were calculated.

\section{Hardness}

The Monsanto hardness tester was used to determine the tablet hardness. The tablet was held between affixed and moving jaw. Scale was adjusted to zero; load was gradually increased until the tablet fractured. The value of the load at that point gives a measure of the hardness of the tablet. It is expressed in $\mathrm{kg} / \mathrm{cm} 2$. For each formulation, the hardness of six tablets was determined and average value was calculated.

\section{Drug content}

Tablets were crushed and the powder equivalent to $100 \mathrm{mg}$ of drug were accurately weighed and transferred to $50 \mathrm{ml}$ volumetric flask. To this flask, sufficient amount of distilled water was added to dissolve the tablets completely. Then, the volume of flask was made up to the mark with same solvent. From this solution, $1 \mathrm{ml}$ of the sample was pipetted out and transferred to $10 \mathrm{ml}$ volumetric flask. The volume in the second flask was made up to the mark with distilled water. From this $0.6 \mathrm{ml}, 0.8 \mathrm{ml}$ and $1 \mathrm{ml}$ samples were withdrawn and volume was made up to $10 \mathrm{ml}$ to maintain concentration within the beer's range. This final diluted solution was estimated UV spectrophotometrically at 286 nm.

\section{Friability}

Twenty tablets samples were weighed accurately and placed in friabilator (Roche Friabilator). After the given specification (4 min at $25 \mathrm{rpm}$ ), loose dust was removed from the tablets. Finally tablets were weighed. The loss in weight indicates the ability of the tablets to withstand this type of wear. The $\%$ friability was then calculated by:

$\%$ Friability $=($ Loss in weight $/$ Initial weight $) \times 100$

\section{In-vitro buoyancy studies}

The in-vitro buoyancy was determined by floating lag time, and total floating time. The tablets were placed in a $100 \mathrm{ml}$ beaker containing $0.1 \mathrm{~N} \mathrm{HCl}$. The time required for the tablet to rise to the surface and float was determined as floating lag time (FLT) and the duration of the time the tablet constantly floats on the dissolution medium was noted as the Total Floating Time respectively (TFT).

\section{Swelling index studies}

The swelling behavior of a dosage unit was measured by studying its weight gain. The swelling index of tablets was determined by placing the tablets in the basket of dissolution apparatus using dissolution medium as $0.1 \mathrm{~N} \mathrm{HCl}$ at $37 \pm 0.5^{\circ} \mathrm{C}$. After 1,4 and $6 \mathrm{~h}$ each dissolution basket containing tablet was withdrawn, blotted with tissue paper to remove the excess water and weighed on the analytical balance (Schimdzu, AX 120). The experiment was performed in triplicate for each time point. Swelling index was calculated by using the following formula

\section{In vitro drug release studies}

$900 \mathrm{ml}$ of $0.1 \mathrm{HCl}$ was placed in the vessel and the USP apparatus -II (Paddle Method) was assembled. The medium was allowed to equilibrate to temp of $37 \pm 0.5^{\circ} \mathrm{C}$. Tablet was placed in the vessel and the vessel was covered, the apparatus was operated for 10 hours at $50 \mathrm{rpm}$. At definite time intervals, $5 \mathrm{ml}$ of the fluid was withdrawn; filtered and again $5 \mathrm{ml}$ of the fresh buffer was replaced. Suitable dilutions were done with the dissolution fluid and the samples were analyzed spectrophotometrically (Systronics, India) for Cefdinir at $286 \mathrm{~nm}$.

\section{RESULTS AND DISCUSSION}

\section{Calibration curve of cefdinir}

The linearity was observed in the concentration range of 2 to $14 \mu \mathrm{g} / \mathrm{ml}$ and thus it follows the Bear-Lambert"s law

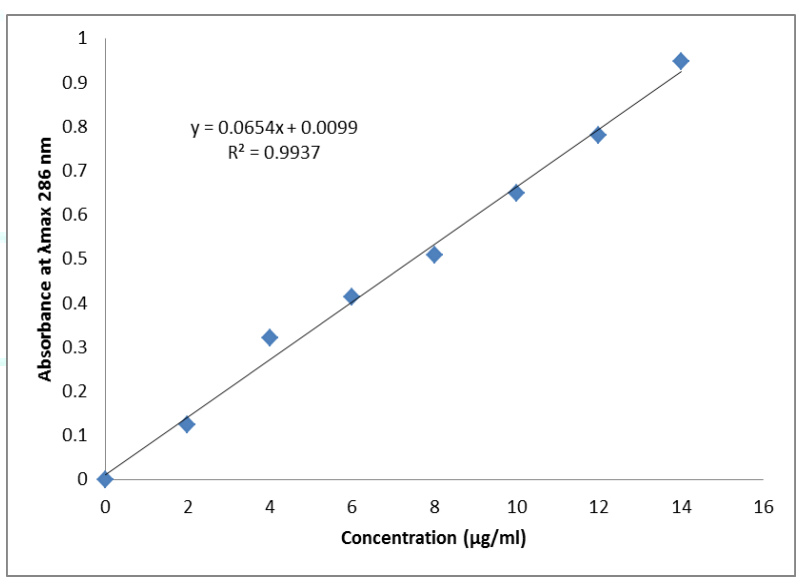

Figure 1: Standard calibration curve of Cefdinir in $0.1 \mathrm{~N} \mathrm{HCL}$

\section{Pre compression studies}

Precompression studies of powdered blend were performed on parameters like bulk density, tapped density, compressibility index, Hausner's ratio and angle of repose as shown in the table below.Angle of repose was found to be $26.62,27.46,28.32,28.06,27.58$ and 28.44. Bulk density was found to be $0.721,0.710,0.415,0.454,0.458$ and 0.445 $\mathrm{g} / \mathrm{cm} 3$, tapped density $0.872,0.879,0.483,0.525,0.505$ and $0.502 \mathrm{~g} / \mathrm{cm} 3$, Hausner's ratio 1.206, 1.251, 1.178, $1.155,1.119$ and 1.123,Carrs index 17.126, 19.714, 15.113, $15.602,12.234$ and 12.585 were found for F1, F2, F3,F4, F5 and F6 formulation respectively and reported in Table 2. 
Table 2: Precompression Studies

\begin{tabular}{|c|c|c|c|c|c|}
\hline Formulation code & Bulk density (gm/mL) & Tapped density (gm/mL) & $\begin{array}{c}\text { Compressibility } \\
\text { index (\%) }\end{array}$ & $\begin{array}{c}\text { Hausner's } \\
\text { ratio }\end{array}$ & $\begin{array}{c}\text { Angle of } \\
\text { repose } \mathbf{(}^{\boldsymbol{\theta}} \text { ) }\end{array}$ \\
\hline F1 & 0.721 & 0.872 & 17.126 & 1.206 & 26.62 \\
\hline F2 & 0.710 & 0.879 & 19.714 & 1.251 & 27.46 \\
\hline F3 & 0.415 & 0.483 & 15.113 & 1.178 & 28.32 \\
\hline F4 & 0.454 & 0.525 & 15.602 & 1.155 & 28.06 \\
\hline F5 & 0.458 & 0.505 & 12.234 & 1.119 & 27.58 \\
\hline F6 & 0.445 & 0.502 & 12.585 & 1.123 & 28.44 \\
\hline
\end{tabular}

\section{Organoleptic and Hardness}

The formulated tablets were evaluated for their organoleptic characters. The tablets are round in shape and white in colour. All the tablets showed elegance in appearance.The hardness of the tablets was measured by Monsonto hardness tester. The hardness of all the formulations was found to be in the range of 7.2 to $7.6 \mathrm{~kg} / \mathrm{cm} 2$. It indicates all the tablets have adequate mechanical strength.

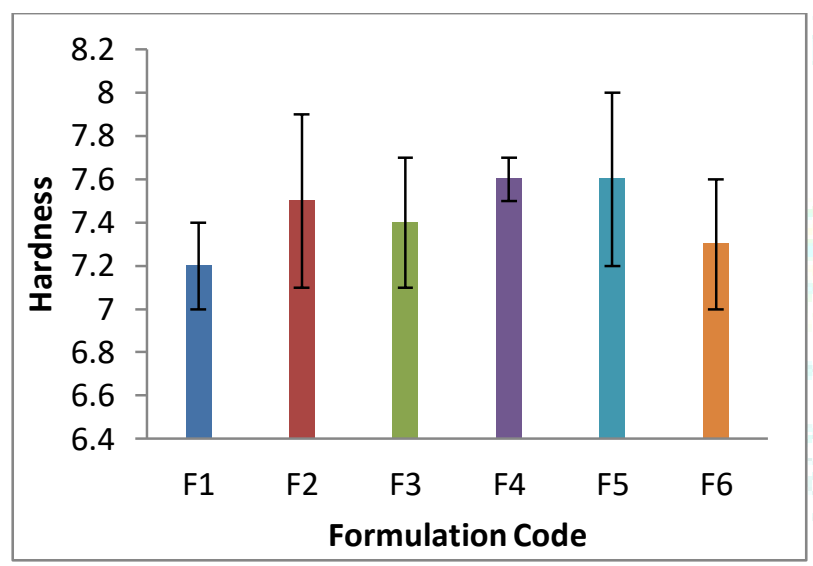

Figure 3: Hardness studies of cefdinir floating tablets formulations

\section{Weight variation}

Twenty tablets of each formulation were selected for weight variation test. The accepted percentage deviation was \pm 7.5 for $130-324 \mathrm{mg}$ weight tablets. It was within the I.P. limit and all the tablets passed the weight variation test.Friability test was carried out by Roche friabilitor. The maximum weight loss should be not more than $1 \%$. All the tablets passed the friability test.

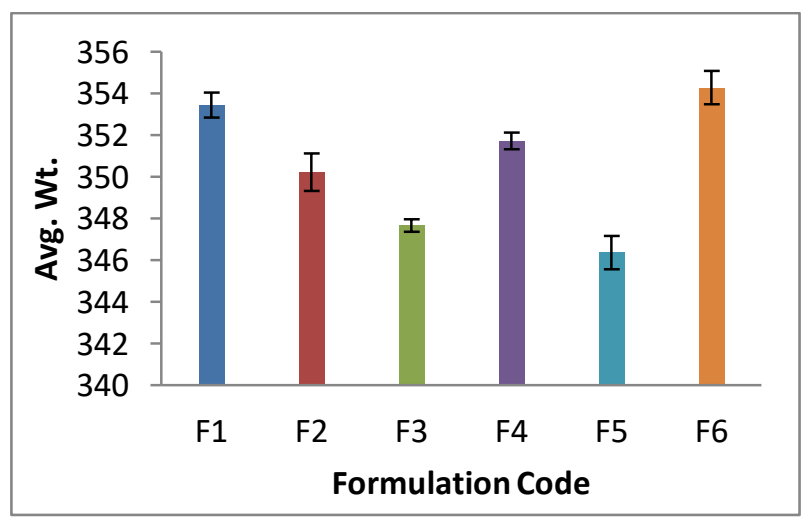

Figure 4: Average weight of cefdinir floating tablets formulations

\section{Total floating time and in-vitro buoyancy studies}

In-vitro buoyancy of the tablets from each formulation (F1 to F6) was evaluated (Figure). Where, the highest and lowest floating lag time (FLT) was observed with the formulation F1 and F6 respectively. The concentration of the natural polymers increases the floating lag time also increases and total floating time observed for all the formulations was $>10$ hours.

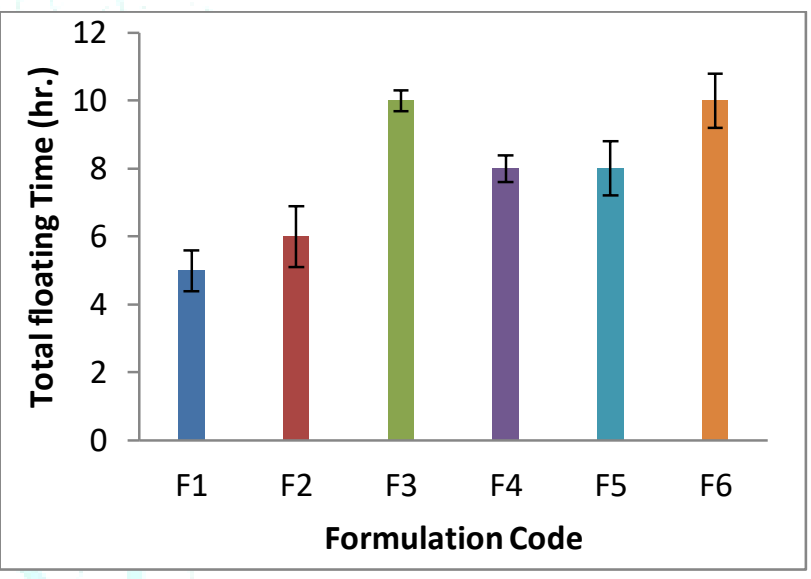

Figure 5: Total floating time studies of cefdinir floating tablets formulations

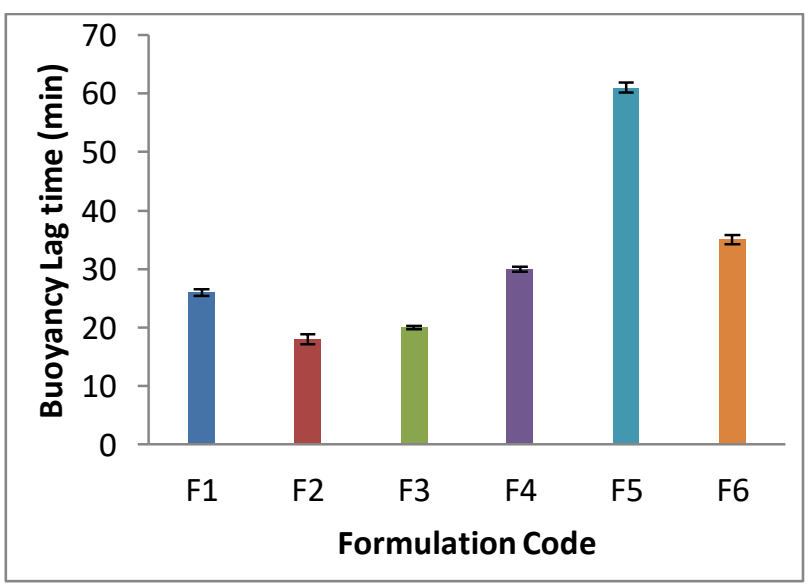

Figure 6: buoyancy lag time (min.) studies of cefdinir floating tablets formulations 


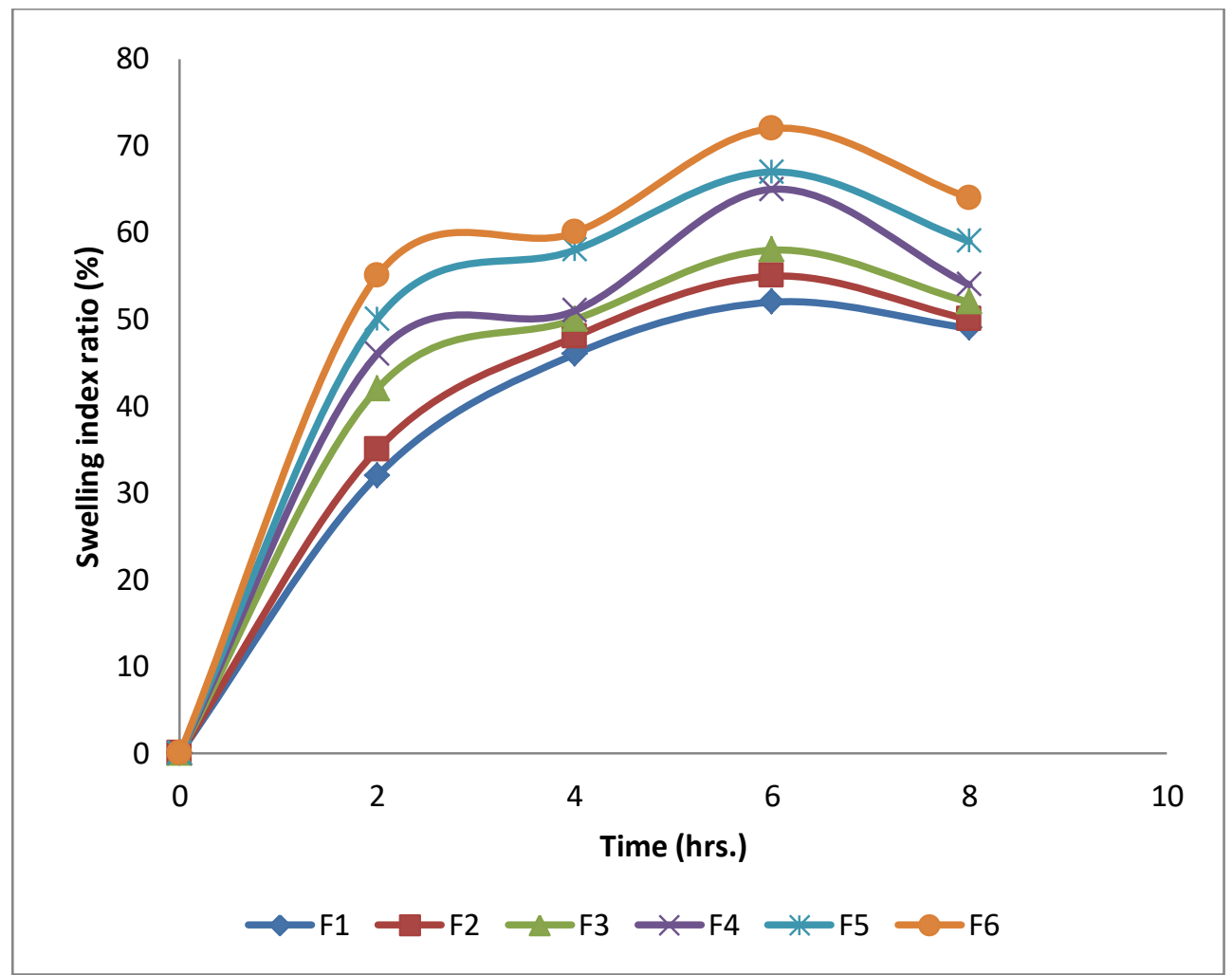

Figure 7: Welling index ratio (\%) studies of floating tablets formulations

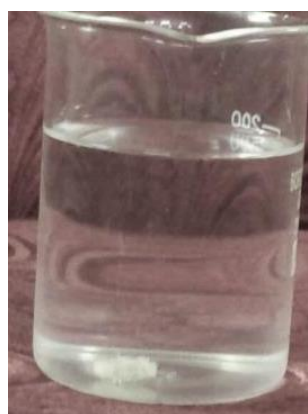

At Intial

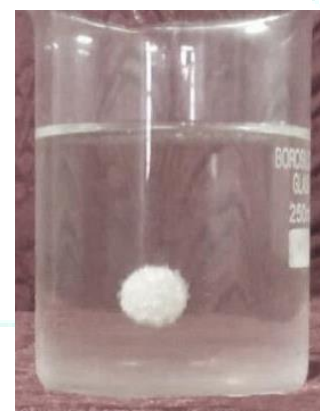

At 10 Sec.

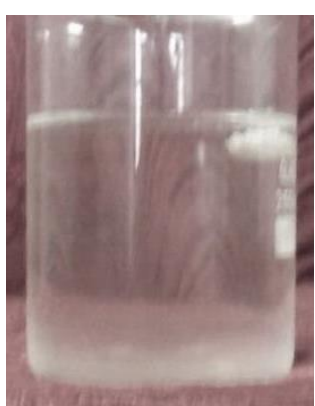

At 10 hrs.

Figure 8: Photographic representation of swelling index ratio (\%) studies 


\section{In-vitro drug release studies}

In-vitro drug release studies were done for the selected study formulations. The drug release was found to show maximum drug release in case of F5 with $97.4 \%$ in $10 \mathrm{hrs}$ as shown in figure 9.

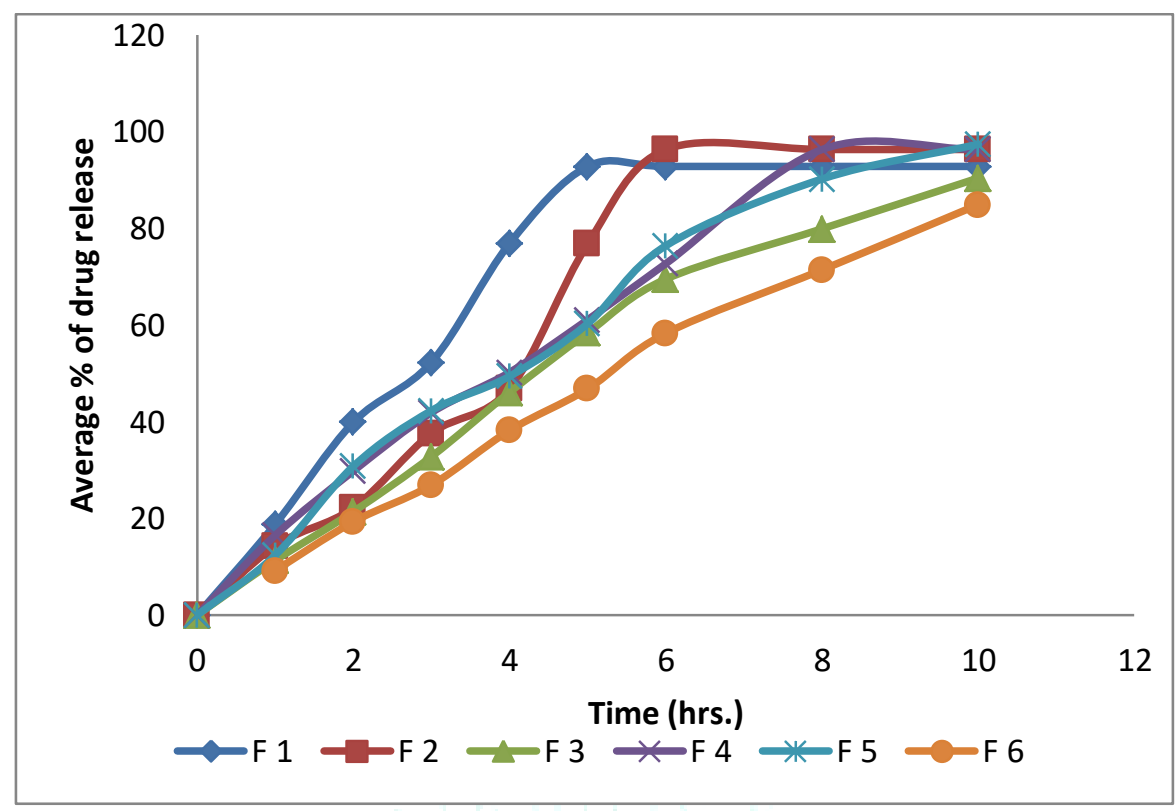

Figure 9: \% of Drug releasestudies of floating tablets formulations

\section{CONCLUSION}

The Cefdinir is antimicrobial agent. In this study the gastroretentive Cefdinir tablet formulation with different excipients for controlled release is successively prepared and evaluated. Formulation showed good release results thus, results of the current study clearly indicate, Cefdinir floating tablet was a stable dosage form and a promising potential of the cefdinir gastroretentive system as an alternative to the conventional dosage form for controlled release. However, further clinical studies are needed to assess the utility of gastroretentive Cefdinir floating formulation.

\section{REFERENCES}

1. Kaushik A, Dwivedi A, Kothari P, Govil A. Floating drug delivery system a significant tool for stomach specific release of cardiovascular drugs. Int. J. Drug Dev. Res., 2012; 4(4):116129.

2. Mathur P, Saroha K, Syan N, Verma S, Kumar V. Floating drug delivery system: An innovative acceptable approachin gastroretentive drug delivery. Arch Appl Sci Res. 2010; 2(2):257-270.

3. Desai S, Bolton SA. A floating controlled release drug delivery system: In vitro-In vivo evaluation. Pharm Res 1993; 10(9):1321-1325.

4. Amrutkar PP, Chaudhari PD, Patil SB. Design and in vitro evaluation of multiparticulate floating drug delivery system of zolpidemtartarate. Colloid Surface B., 2012; 89:182-187.
5. Oxford Handbook of Infectious Diseases and Microbiology. OUP Oxford; ISBN 326 9780191039621, 2009, pp. 56.

6. Ponchel G, Irache J-M. Specific and non-specific bioadhesive participate systems for oral delivery to the gastrointestinal tract. Adv Drug Deliver Rev 1998; 34:191-219.

7. Deshpande AA, Shah NH, Rhodes CT, Malick W. Development of a novel controlled release system for gastric retention. Pharm. Res., 1997; 14:815-819.

8. Davis SS, Stockwell AF, Taylor MJ et al. The effect of density on the gastric emptying of single- and multiple-unit dosage forms. Pharm. Res., 1997; 3: 208-213.

9. Klausner EA, Lavy E, Friedman M, Hoffman A. Expandable gastroretentive dosage forms. J Control Release 2003; 90:143162.

10. Kedzierewicz F, Thouvenot P, Lemut J, Etienne A, Hoffman M, Maincent P. Evaluation of peroral silicone dosage forms in humans by gamma-scintigraphy. J Control Release. 1999; 58:195-205.

11. Groning R, Heun G. Oral dosage forms with controlled gastrointestinal transit. Drug Dev Ind Pharm. 1984; 10:527539.

12. Chawla G, Gupta P, Koradia V, Bansal AK. Gastroretention a means to address intestinal drug absorption. Pharm Technol 2003; 27:50-68.

13. Singh BN and Kim KH. Floating drug delivery systems: an approach to oral controlled drug delivery via gastric retention. J. Control. Release. 2000; 63:235-239. 